\title{
Study of the association between CD28/CTLA-4 expression and disease activity in juvenile idiopathic arthritis
}

\author{
LEI ZHANG, HUI LIANG, HUI GUAN and HUALIN LIU \\ Department of Hematology, Qingdao Women and Children's Hospital, Qingdao, Shandong 266034, P.R. China
}

Received February 19, 2014; Accepted January 20, 2015

DOI: $10.3892 /$ etm.2015.2295

\begin{abstract}
The aim of the present study was to investigate the immune function of children with juvenile idiopathic arthritis (JIA). Flow cytometry and three-color direct immunofluorescence were used to examine cluster of differentiation (CD) $3^{+}$T-lymphocyte subsets and CD28/cytotoxic T-lymphocyte-associated protein 4 (CTLA-4) expression in whole blood (using the no-wash method) from 36 children with JIA and 39 healthy children. During the active phase of JIA, CD28 expression on CD4 ${ }^{+} \mathrm{T}$ cells in children with JIA was significantly reduced; thus, $\mathrm{CD} 4^{+} \mathrm{CD} 28^{-} \mathrm{T}$-cell frequency increased, suggesting that $\mathrm{CD} 4^{+} \mathrm{T}$-cell and $\mathrm{CD} 4^{+} \mathrm{CD} 28^{-} \mathrm{T}$-cell apoptosis was inhibited in patients with JIA. The continued survival of these immune-active $\mathrm{T}$ lymphocytes may promote the occurrence and development of JIA. CTLA-4 expression levels on $\mathrm{CD}^{+}$and $\mathrm{CD}^{+} \mathrm{T}$ cells in children with JIA during the active phase were significantly higher than those in normal controls. As the majority of $\mathrm{CD}^{+} \mathrm{T}$ cells in patients with JIA are CD28, they cannot be inactivated by the interaction between CTLA-4 and B7, leading to continuously high levels of CTLA-4 expression on the surface of $\mathrm{CD} 4^{+} \mathrm{T}$ cells without functional effect. Hence, T lymphocytes are continuously kept in a highly activated state that is difficult to stop. During the resting phase, the $\mathrm{CD}^{+}$and $\mathrm{CD}^{+} \mathrm{T}$-cell counts in children with JIA were similar to normal, and CD28 expression was also normal. This suggests that the frequency of $\mathrm{CD} 4^{+} \mathrm{CD} 28$ $\mathrm{T}$ cells can be used as an indicator of the active phase of JIA. CTLA-4 expression on the surface of T cells in children with JIA during the resting phase was also similar to that in normal controls, suggesting that abnormal lymphocyte activation plays an important role in the active phase of JIA.
\end{abstract}

Correspondence to: Dr Hui Liang, Department of Hematology, Qingdao Women and Children's Hospital, 217 Liaoyangxi Road, Qingdao, Shandong 266034, P.R. China

E-mail: 1hqdetne@126.com

Key words: juvenile idiopathic arthritis, cluster of differentiation 28, cytotoxic T lymphocyte-associated protein 4 , costimulatory molecules

\section{Introduction}

Juvenile idiopathic arthritis (JIA) is a very common childhood autoimmune disease (1). Its main features are chronic arthritis associated with multi-system involvement (2). Its clinical manifestations are diverse and early diagnosis is challenging. The disease is chronic and persistent and tends to involve repeated episodes. During later stages, it can cause deformity and dysfunction of the joints and blindness, severely impairing the physical and mental health of children (3). Studies have found that a variety of immune injuries are involved in the pathogenesis of JIA $(1,4,5)$. Clarification of the substances and methods underlying these immune injuries should provide a valuable basis for the treatment of JIA (6). The production of various cytokines marks the occurrence of abnormalities of lymphocyte function during the active period of JIA (6). It has been confirmed that dual signal stimuli are required for the activation of lymphocytes. The interaction of B7 molecules expressed on antigen-presenting cells (APCs) and the ligands cluster of differentiation (CD)28 and cytotoxic T-lymphocyte-associated protein 4 (CTLA-4) expressed on T-cells. CD28 provides the most important co-stimulatory signal, which plays an important role in initiating and maintaining the activation and proliferation of T cells. CTLA-4 belongs to the immunoglobulin (Ig) super-family, having $31 \%$ homology with CD28 at the amino acid level. The function of CTLA-4 opposes that of CD28 in lymphocyte activation (7). On combining with B7, CTLA-4 inhibits CD28 ${ }^{+}$T lymphocytes and effectively terminates their activation and proliferation (8). However, whether CTLA-4 is expressed effectively during the active period of JIA and has the same inhibitory effect on the CD28- T lymphocytes predominant in JIA has never been reported. In the present study, flow cytometry was used to measure the expression of CD28/CTLA-4 on the surface of $\mathrm{CD}^{+}$and $\mathrm{CD}^{+} \mathrm{T}$ lymphocytes in peripheral blood and to investigate the correlation with JIA activity. The goal was to understand the role of abnormal lymphocyte activity in the active phase of JIA and to provide a theoretical basis for its clinical treatment and improvements in prognosis.

\section{Materials and methods}

Clinical data. A total of 36 children with JIA admitted to the Affiliated Hospital of Qingdao University Medical College, Qingdao Children's Hospital (Qingdao, China) from 
October 2010 to July 2011 were included in the JIA group. All patients were diagnosed according to diagnostic and classification standards specified by the International Union of Rheumatology $(9,10)$. The patient group consisted of 16 males and 20 females aged 5-14 years (mean, 7.5 years). The normal control group contained 39 healthy children consisting of 17 males and 22 females aged 4-13 years (mean, 6.9 years). The age and gender ratios between the two groups were not significantly different. None of the enrolled subjects had cancer, a family history of autoimmune disease, history of infectious disease in the past 3 months, or received any glucocorticoid or other immunosuppressive treatment within the past 6 months. Other autoimmune diseases were also excluded. The experiments were performed with informed consent from all patients and their families.

Ethical considerations. This study was conducted in compliance with the Declaration of Helsinki (http://www.wma.net/ en/30publications/10policies/b3/index.html). It was approved by the Faculty of Medicine Ethics Committee of Qingdao Women and Children's Hospital and Qingdao University Medical College in July 2009. Before the study began, full details were given to all participants or their guardians, who were assured of confidentiality and gave their informed written consent. All data were reported in a collective fashion, and participants were able to withdraw at any time without affecting their children's treatment.

Patient groupings. Among the 36 children in the JIA group, 7 had oligoarticular-type JIA, 16 were polyarticularrheumatoid-factor negative, 12 had systemic JIA and one had JIA associated with enthesitis. The longest follow-up was for 2 years and 7 months, while the shortest was 3 months. For follow-ups, the patients visited the hospital every 1-2 weeks to undergo routine blood tests as well as C-reactive protein (CRP) and erythrocyte sedimentation rate (ESR) tests. Patients showing severe symptoms were hospitalized for treatment.

Patients were stratified into the following groups: i) Initial active phase: Patients were positively diagnosed with JIA, showing distinct clinical symptoms accompanied by increased values in indicators for inflammation in peripheral blood, such as increased white blood cell count, increased CRP and quickened ESR. ii) Resting phase: Patients were positively diagnosed with JIA. After treatment, however, clinical symptoms disappeared, and results from routine blood tests as well as of CRP and ESR were all normal throughout the follow-ups. iii) Controls: Concurrent controls were physically examined in the hospital.

Collection of clinical data. Clinical information of all enrolled patients was recorded in detail, including name, gender, age, treatment and follow-ups. Laboratory tests included the blood routine tests as well as the CRP and ESR tests.

\section{Methods}

Instruments and reagents. A BD FACSCalibur flow cytometer (BD Biosciences, San Jose, CA, USA) and fluorescence-labeled mouse anti-human monoclonal antibodies (mAbs; \#FHP0041-100 and \#11524-MM026; dilution, 1:10;
BioLegend, Inc., San Diego, CA, USA) were used in the flow cytometric analysis.

Methods. i) Blood sampling. For all subjects, $3 \mathrm{ml}$ venous blood was collected using heparin as anticoagulant and diluted with an equal volume of phosphate-buffered saline (PBS). Lymphocytes were then isolated using Ficoll separation fluid (BioLegend Inc.) to obtain a single-cell layer, rinsed with PBS and centrifuged at $1,000 \mathrm{x}$ g for $15 \mathrm{~min}$. The supernatant was discarded. The cells were then resuspended in PBS, and the cell concentration was adjusted to $\sim 5 \times 10^{6}$ cells $/ \mathrm{ml}$.

ii) Cell staining. Cells were surface stained with three-color labeling using antibodies against CD3, CD4, CD8 and CTLA-4 (CD152). Specifically, the peripheral blood mononuclear cell suspension was added to the bottom of a flow tube and evenly divided into the three samples. The first sample was treated with phycoerythrin (PE)-Cy5-labeled CD3, fluorescein isothiocyanate (FITC)-labeled CD4 and PE-labeled CD8 mAbs to measure the T-lymphocyte subset frequency in peripheral blood. The second sample was treated with PE-Cy5-labeled CD4 and PE-labeled CD152 mAbs to measure CTLA-4 expression on $\mathrm{CD}^{+}{ }^{+} \mathrm{T}$ cells. The third sample was treated with PE-Cy5-labeled CD8 and PE-labeled CD152 mAbs to measure CTLA-4 expression on CD8 ${ }^{+} \mathrm{T}$ cells. Each sample was mixed with $20 \mu \mathrm{l}$ of the appropriate mAbs, incubated at room temperature in the dark for $20 \mathrm{~min}$, and then centrifuged at $250 \mathrm{x}$ g for $5 \mathrm{~min}$; the supernatants were discarded. Then, $2 \mathrm{ml}$ PBS wash solution was added and mixed well to resuspend the cells. The cells were centrifuged at $250 \mathrm{x} \mathrm{g}$ for $5 \mathrm{~min}$, and the supernatant was discarded. Flow cytometry wash solution (200 $\mu \mathrm{l}$; BioLegend Inc.) was added to resuspend the cell pellets, and the suspension was loaded onto the cytometer for collection.

iii) Flow cytometric analysis. In a scatter plot, forward scatter (FSC) and side scatter (SSC) parameters were used to set the threshold and determine lymphocyte position. The PE-Cy5-positive cell population was first selected, followed by determination of the CD4 and CD 8 cell subpopulation percentages among PE-Cy5-positive cells. CTLA-4 expression levels in $\mathrm{CD}^{+}$and $\mathrm{CD}^{+} \mathrm{T}$ cells were then calculated. A total of 10,000 cells were analyzed per sample.

Statistical analysis. SPSS software, version 13.0 (SPSS, Inc., Chicago, IL, USA) was used to analyze data. Data are presented as mean \pm standard deviation. A normality test was first performed on all data; comparisons that passed the normality test were analyzed by a Student's t-test, and those that did not were analyzed with an approximate t-test. A value of $\mathrm{P}<0.05$ was considered to be statistically significant.

\section{Results}

$C D 4^{+} C D 28^{+}$and $C D 8^{+} C D 28^{+} T$-cell frequency. During the active phase of the disease, the $\mathrm{CD} 4^{+} \mathrm{CD} 28^{+}$and $\mathrm{CD} 8^{+} \mathrm{CD} 28^{+}$ $\mathrm{T}$ cell frequencies in the peripheral blood of children with JIA were significantly lower compared with those in the normal control group $(\mathrm{P}<0.01$; Table I and Fig. 1).

$C D 4^{+} C D 28^{-}, C D 4^{+} C T L A-4^{+}$and $C D 8^{+} C T L A-4^{+}$-cell frequency. During the active phase of the disease, the $\mathrm{CD} 4{ }^{+} \mathrm{CD} 28^{-} \mathrm{T}$-cell frequency in the peripheral blood of chil- 
Table I. Frequency of CD28 $8^{+} \mathrm{T}$ cells in the peripheral blood of patients with JIA during the active phase of the disease.

\begin{tabular}{lccc}
\hline Group & No. of cases & $\mathrm{CD}^{+} \mathrm{CD} 28^{+}(\%)$ & $\mathrm{CD}^{+} \mathrm{CD} 28^{+}(\%)$ \\
\hline JIA & 36 & $7.46 \pm 0.41^{\mathrm{a}}$ & $10.94 \pm 1.10^{\mathrm{a}}$ \\
Normal & 39 & $37.13 \pm 1.92$ & $13.24 \pm 0.84$
\end{tabular}

Values are presented as the mean \pm standard deviation. ${ }^{\mathrm{a}} \mathrm{P}<0.01 \mathrm{com}-$ pared with the normal control group. $\mathrm{CD}$, cluster of differentiation; JIA, juvenile idiopathic arthritis.

Table II. Frequency of CD28- T cells in the peripheral blood of patients with JIA during the active phase of disease.

\begin{tabular}{lccc}
\hline Group & No. of cases & $\mathrm{CD}^{+} \mathrm{CD} 28^{-}(\%)$ & $\mathrm{CD}^{+} \mathrm{CD} 28^{-}(\%)$ \\
\hline JIA & 36 & $7.81 \pm 1.89^{\mathrm{a}}$ & $20.30 \pm 10.15$ \\
Normal & 39 & $1.91 \pm 0.69$ & $20.03 \pm 10.02$ \\
\hline
\end{tabular}

Values are presented as the mean \pm standard deviation. ${ }^{\mathrm{a}} \mathrm{P}<0.01 \mathrm{com}-$ pared with the normal control group. $\mathrm{CD}$, cluster of differentiation; JIA, juvenile idiopathic arthritis.

Table III. Frequency of CTLA-4 ${ }^{+} \mathrm{T}$ cells in the peripheral blood of patients with JIA during the active phase.

\begin{tabular}{lccc}
\hline Group & No. of cases & $\begin{array}{c}\text { CD4 }{ }^{+} \text {CTLA-4 } \\
(\%)\end{array}$ & $\begin{array}{c}\text { CD8 }{ }^{+} \text {CTLA-4 } \\
(\%)\end{array}$ \\
\hline JIA & 36 & $5.15 \pm 0.52^{\mathrm{a}}$ & $1.80 \pm 0.20^{\mathrm{a}}$ \\
Normal & 39 & $2.35 \pm 0.29$ & $0.73 \pm 0.20$ \\
\hline
\end{tabular}

Values are presented as the mean \pm standard deviation. ${ }^{\mathrm{a}} \mathrm{P}<0.01 \mathrm{com}-$ pared with the normal control group. Among all tested $\mathrm{CD} 4^{+} \mathrm{T}$ cells, $86 \%$ were CD28. CD, cluster of differentiation; CTLA-4, cytotoxic T-lymphocyte-associated protein 4; JIA, juvenile idiopathic arthritis.

dren with JIA was significantly higher compared with that in the normal control group ( $\mathrm{P}<0.01$; Fig. 2 and Table II), whereas the frequencies of $\mathrm{CD} 4^{+} \mathrm{CTLA}-4^{+}$and $\mathrm{CD} 8^{+} \mathrm{CTLA}-4^{+} \mathrm{T}$ cells were significantly higher compared with those in the normal control group $(\mathrm{P}<0.01$; Table III).

$C D 4^{+}$and $C D 8^{+} T$-cell counts. During the active phase of the disease, the $\mathrm{CD} 4^{+} \mathrm{T}$-cell count in the peripheral blood of children with JIA was significantly higher compared with that in the normal control group $(\mathrm{P}<0.01)$, where $\mathrm{CD} 4^{+} \mathrm{CD} 28^{-}$cells mostly accounted for the increase in $\mathrm{CD} 4^{+} \mathrm{T}$-cell frequency. By contrast, $\mathrm{CD} 8^{+} \mathrm{T}$-cell counts were significantly reduced in the JIA group $(\mathrm{P}<0.01$; Table IV).

During the resting phase, the $\mathrm{CD} 4^{+}$and $\mathrm{CD} 8^{+} \mathrm{T}$-cell counts in the peripheral blood of children with JIA were not significantly different from those in normal controls $(\mathrm{P}>0.05$; Table V).
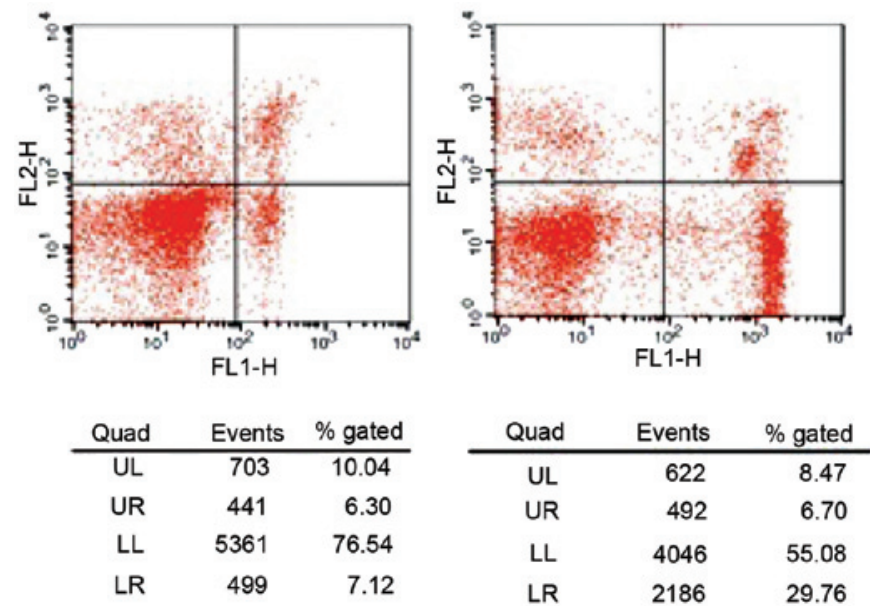

Figure 1. Frequency of cluster of differentiation (CD) $28^{+} \mathrm{T}$ cells in the peripheral blood of patients with juvenile idiopathic arthritis during the active phase of the disease. UL, upper left; UR, upper right; LL, lower left; LR, lower right; FL1, fluorescein isothiocyanate; FL2, phycoerythrin.
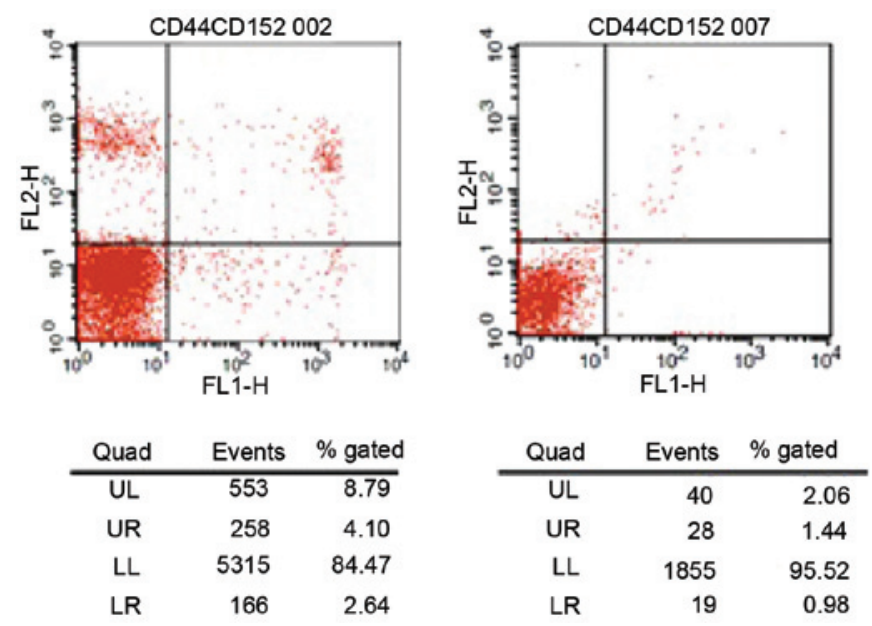

Figure 2. Frequency of cluster of differentiation (CD) $28^{-} \mathrm{T}$ cells in the peripheral blood of patients with juvenile idiopathic arthritis during the active phase of the disease. UL, upper left; UR, upper right; LL, lower left; LR, lower right; FL1, fluorescein isothiocyanate; FL2, phycoerythrin.

CD28 $8^{+}$and CTLA $-4^{+}$frequency during the resting phase. During the resting phase of the disease, the $\mathrm{CD} 28^{+}$and CTLA- $4^{+}$frequencies in the $\mathrm{CD} 4^{+}$or $\mathrm{CD} 8^{+} \mathrm{T}$-cell populations in the peripheral blood of children with JIA were not significantly different from those in the normal control group ( $\mathrm{P}>0.05$; Tables VI and VII).

\section{Discussion}

JIA is the most common connective-tissue disease that occurs in children and is a leading cause of disability and blindness (6). Its main features are chronic synovitis and symmetrically destructive joint disease accompanied by involvement of multiple other systems in the body. In 2001, the International League of Associations for Rheumatology named the condition defined by joint swelling that persists for more than 6 weeks due to an unknown cause in children under 16 years old as juvenile idiopathic arthritis, which was 
Table IV. Changes in T-cell subsets in patients with JIA during the active phase.

\begin{tabular}{lccc}
\hline Group & No. of cases & $\mathrm{CD}^{+} \mathrm{CD}^{+}(\%)$ & $\mathrm{CD}^{+} \mathrm{CD} 8^{+}(\%)$ \\
\hline JIA & 36 & $40.63 \pm 4.14^{\mathrm{a}}$ & $23.27 \pm 3.37^{\mathrm{a}}$ \\
Normal & 39 & $31.82 \pm 3.12$ & $27.72 \pm 3.23$ \\
\hline
\end{tabular}

Values are presented as the mean \pm standard deviation. ${ }^{\mathrm{a}} \mathrm{P}<0.01$ compared with the normal control group. JIA, juvenile idiopathic arthritis; $\mathrm{CD}$, cluster of differentiation.

Table V. Changes in T-cell subsets in patients with JIA during the resting phase.

\begin{tabular}{lccc}
\hline Group & No. of cases & $\mathrm{CD}^{+}{ }^{+} \mathrm{CD} 4^{+}(\%)$ & $\mathrm{CD}^{+} \mathrm{CD}^{+}(\%)$ \\
\hline JIA & 36 & $33.31 \pm 2.58$ & $26.27 \pm 0.40$ \\
Normal & 39 & $31.82 \pm 3.12$ & $27.72 \pm 3.23$ \\
\hline
\end{tabular}

Values are presented as the mean \pm standard deviation. $\mathrm{P}>0.05$ for the JIA group compared with the normal control group. JIA, juvenile idiopathic arthritis; $\mathrm{CD}$, cluster of differentiation.

further divided into seven subtypes (10). There is significant heterogeneity among these subtypes, including modes of onset and numerous clinical manifestations that can sometimes make diagnosis rather challenging. While symptoms can be alleviated and joint function restored to normal following treatment in $75 \%$ of patients, lifelong symptoms, significant disability, or even mortality due to concurrent infection or starch-like degeneration may occur in some children (11). Hence, the pathogenesis underlying JIA has become a popular research topic worldwide, with the aim of finding more effective methods for early diagnosis and treatment to reduce the morbidity and mortality of this disease. Currently, research into the underlying causes of JIA is mainly focused on aspects such as genetics, environment, and infection. In terms of JIA pathogenesis, the majority of scholars believe that JIA is a type of autoimmune disease and that abnormal immune function, particularly abnormal cellular immune function, is an important mechanism underlying JIA. Inflammatory cells infiltrating synovial tissues in JIA are mainly activated T cells, suggesting that the pathologic autoimmune response may be activated by antigens and mediated by $\mathrm{T}$ cells (12). Since these activated $\mathrm{T}$ cells play an important role in the pathogenesis of JIA by affecting cell-cell contact and producing cytokines (13), inhibiting the function of excessively activated $\mathrm{T}$ cells may theoretically inhibit inflammatory processes and improve disease outcome in patients with JIA.

In addition to stimulating primary signals provided by T-cell receptor (TCR)-CD3-major histocompatibility complex (MHC) interaction, T-lymphocyte activation also requires secondary signals for co-stimulation. During an immune response, secondary signal expression depends on the normal transfer of primary signals. If the latter is hindered, the immune response cannot proceed. $\mathrm{T}$ lymphocytes cannot be
Table VI. Frequency of CD28 $8^{+} \mathrm{T}$ cells in the peripheral blood of patients with JIA during the resting phase.

\begin{tabular}{lccc}
\hline Group & No. of cases & $\mathrm{CD}^{+} \mathrm{CD} 28^{+}(\%)$ & $\mathrm{CD}^{+} \mathrm{CD} 28^{+}(\%)$ \\
\hline JIA & 36 & $36.43 \pm 1.52$ & $12.97 \pm 0.53$ \\
Normal & 39 & $37.13 \pm 1.67$ & $13.24 \pm 0.84$ \\
\hline
\end{tabular}

Values are presented as the mean \pm standard deviation. $\mathrm{P}>0.05$ for the JIA group compared with the normal control group. JIA, juvenile idiopathic arthritis; $\mathrm{CD}$, cluster of differentiation.

Table VII. Frequency of CTLA-4 $4^{+} \mathrm{T}$ cells in the peripheral blood of patients with JIA during the resting phase.

\begin{tabular}{lccc}
\hline Group & No. of cases & $\begin{array}{c}\text { CD4 }{ }^{+} \text {CTLA-4 } \\
(\%)\end{array}$ & $\begin{array}{c}\text { CD8 }^{+} \text {CTLA-4 }^{+} \\
(\%)\end{array}$ \\
\hline JIA & 36 & $2.41 \pm 0.25$ & $0.78 \pm 0.11$ \\
Normal & 39 & $2.35 \pm 0.29$ & $0.73 \pm 0.20$ \\
\hline
\end{tabular}

Values are presented as the mean \pm standard deviation. $\mathrm{P}>0.05$ for the JIA group compared with the normal control group. $\mathrm{CD}$, cluster of differentiation; CTLA-4, cytotoxic T-lymphocyte-associated protein 4 ; JIA, juvenile idiopathic arthritis.

effectively stimulated without secondary signals, resulting in clonal anergy or programmed cell death (PCD). Excessive co-stimulatory signaling may lead to T-cell overactivation and, ultimately, autoimmune disease (13). CD28 and CTLA-4 were the first costimulatory molecules confirmed to play a key role in T-cell activation by interaction with B7 (14) during an immune response, where CD28 transfers co-stimulatory signals, enhances T-cell activation, and upregulates downstream signal transmission, while CTLA-4 transfers inhibitory signals, downregulates the activation of B cells and macrophages, reduces pro-inflammatory factor secretion and ultimately leads to anergy (15). In a rat adjuvant arthritis (AA) model, Rodriguez-Palmero et al (16) found that stimulating CD28 with a monoclonal antibody promoted Th2 function and regulatory T-cell proliferation, thus providing effective protection against AA. Clinically, immune function disorder correlates with abnormal T-lymphocyte activation and abnormal co-stimulatory molecule expression in adult patients with rheumatoid arthritis (RA) and rheumatoid inflammation (17). Therefore, investigating co-stimulatory molecule expression levels and abnormal T-cell activation in children with JIA should help in further understanding the pathogenesis underlying JIA and provide a theoretical basis for the development of biological treatments against JIA.

CTLA-4, discovered by screening mouse $\mathrm{CD}^{+} \mathrm{T}$-cell cDNA (18), belongs to the Ig superfamily and shares $31 \%$ homology with CD28 at the amino acid level (19). CTLA-4 contains an IgV-like extramembranous functional domain, a transmembrane domain, and a short, conserved functional intracellular domain. Complete CTLA-4 molecules mainly exist on the surface of $\mathrm{T}$ cells in dimeric form and are only 
expressed on activated $\mathrm{CD}^{+}$and $\mathrm{CD}^{+} \mathrm{T}$ cells. While the level of CTLA-4 expression is only 2-3\% of the CD28 expression level, its affinity for B7 is 10-100-fold greater than that for CD28 (7). As a co-stimulatory signal for lymphocyte activation, the function of CTLA-4 opposes that of CD28. At the beginning of the T-cell response, CD28 expression mediates T-cell activation and clonal expansion by binding to B7 on APCs. Activated T cells gradually increase CTLA-4 expression, which then competes against CD28 for binding to B7 and functions as a strong inhibitory signal to terminate excessive T-cell proliferation and activation. This maintains the immune response in a relatively balanced state. When antigen and co-stimulatory effects are weak, CTLA-4 maintains T cells in a resting state to avoid unnecessary T-cell response. Such CTLA-4-mediated mechanisms play a positive role in immune tolerance to autoantigens (8).

The ligands for CTLA-4 and CD28 on the surface of T lymphocytes are B7-1 (CD80) and B7-2 (CD86), both of which are expressed on the surface of APCs and activated $\mathrm{T}$ cells. The genes for both molecules are located on human chromosome 3 , and the structural features of these proteins indicate that they belong to the Ig superfamily (19). While examining adhesion molecules, Linsley et al (20) first demonstrated that CD28 binds to B7-1 to co-stimulate cells. CTLA-4 was later found to bind B7-1 as well, although the effect was the opposite of that of B7-1 binding to CD28. CD28 overexpression can lead to T-cell overactivation; if this cannot be inhibited by CTLA-4, immune disorders can develop. Following an excess of CD28 expression, CD28 molecules on cells that have been repeatedly stimulated by antigens fall off the surface to form CD28- ${ }^{-}$cells. If CD28 function is normal, it can upregulate the expression of antiapoptotic gene Bcl-XL in target cells, block T-cell activation, and induce apoptosis, thus promoting $\mathrm{T}$-cell proliferation that sustains auto-responses (21). Otherwise, immunosenescence occurs, and apoptosis is impaired. A number of studies have confirmed that CTLA-4 is involved in autoimmunity, and its expression is significantly increased in many types of autoimmune diseases, including RA, systemic lupus erythematosus, systemic sclerosis, Behcet's disease (22), and ankylosing spondylitis (23). CTLA-4-Ig, a soluble fusion protein formed by fusing the extramembrane domain of human CTLA-4 and the $\mathrm{C}$ domain of $\mathrm{Ig}$, blocks the interaction between $\mathrm{B} 7$ and its receptor molecule CTLA-4 by binding to B7. In fact, CTLA-4-Ig has shown some therapeutic effect in treating autoimmune diseases.

In the present study, CD28/CTLA-4 on the surface of $\mathrm{T}$ lymphocytes was examined in the peripheral blood of 36 children with JIA during the active and resting phases of the disease by flow cytometry. $\mathrm{CD} 4^{+} \mathrm{T}$-cell counts increased during the active phase of JIA, suggesting that $\mathrm{CD}^{+}{ }^{+} \mathrm{T}$-cell apoptosis is significantly impaired at disease onset. The immune-active $\mathrm{T}$ cells within the $\mathrm{CD} 4^{+} \mathrm{CD} 28^{-}$compartment that persistently survive, then induce inflammation-mediated pathological damage that is characteristic of JIA, producing a series of clinical symptoms within the patient. It may, therefore, be speculated that inhibiting the immune activity or increasing the rate of apoptosis of these cells may alleviate the inflammatory responses in JIA and improve the condition of the patients.
The present study also demonstrated that CTLA-4 expression on the surface of $\mathrm{CD}^{+} \mathrm{T}$ cells in JIA patients was significantly higher than that in normal controls during the active phase of the disease. In addition, the majority of $\mathrm{CD}^{+}{ }^{+} \mathrm{T}$ cells in children with JIA were CD28-. Therefore, CTLA-4 is highly expressed, mainly on the surface of $\mathrm{CD} 4^{+} \mathrm{CD} 28^{-} \mathrm{T}$ cells. As CTLA-4 expressed on the surface of $\mathrm{CD} 4^{+} \mathrm{CD} 28^{-} \mathrm{T}$ cells cannot effectively bind to $\mathrm{B} 7$, it cannot effectively inhibit the immune activity of $\mathrm{CD} 4{ }^{+} \mathrm{CD} 28-$ $\mathrm{T}$ cells or accelerate their apoptosis. Hence, the number of $\mathrm{CD}^{+} \mathrm{CD} 28^{-} \mathrm{T}$ cells is substantially increased. These increased $\mathrm{CD} 4^{+} \mathrm{CD} 28^{-} \mathrm{T}$ lymphocytes remain immunologically active, and their function changes. For example, their ability to activate Th1 cells is enhanced (24); they can secrete IFN- $\gamma$ and IL-1, stimulate macrophages to release matrixdegrading protease, and directly cause damage to blood vessels, tissues and organs in patients with RA (25). Thus, these changes in CD28/CTLA-4 occurring during the active phase of disease are key factors contributing to the pathogenesis of JIA. By contrast, CD28/CTLA-4 expression on the surface of $\mathrm{T}$ cells during the resting phase of the disease is restored to normal levels. Therefore, the excessive expression of ineffective CTLA-4 together with low CD28 expression levels can serve as an indicator for the active phase of JIA. In clinical practice, the data from the present study also suggest that intervening treatments that promote $\mathrm{CD} 4{ }^{+} \mathrm{CD} 28$ T-lymphocyte apoptosis may stop the development of JIA.

In the present study, $\mathrm{CD} 4^{+} \mathrm{T}$-cell counts were significantly higher during the active phase of the disease in patients with JIA compared with those in normal controls, suggesting that CD4 ${ }^{+}$T-lymphocyte apoptosis is impaired. Hence, abnormally activated $\mathrm{T}$ lymphocytes, particularly $\mathrm{CD} 4^{+} \mathrm{T}$ lymphocytes, are the main cell subsets inducing immune damage in JIA. High CTLA-4 expression levels cannot reduce the activity of these cells, and the increased number $\mathrm{CD} 4^{+} \mathrm{T}$ lymphocytes is mainly accounted for by $\mathrm{CD} 4^{+} \mathrm{CD} 28^{-} \mathrm{T}$ cells. Therefore, inhibiting the activation of these cells may alleviate JIA. Studies have confirmed that $\mathrm{CD} 4^{+} \mathrm{CD} 28^{-}$is an optimal biological marker for an aging immune system (26-28). T cells enter cellular senescence following multiple cell-division cycles, which is characterized by three main features (29) as follows: i) functional changes (e.g., production of a large amount of inflammatory cytokines); ii) telomere shortening and eventual cessation of proliferation; and iii) tolerance to apoptosis. The loss of CD28 is a well-known phenotypic change associated with cellular senescence. It has been suggested that CD28- T cells represent aging lymphocytes (30), and the results of the present study are consistent with this hypothesis.

The present study used flow cytometry to examine co-signaling molecules CD28/CTLA-4 on the surface of $\mathrm{T}$ cells in the peripheral blood of children with JIA to study the association between CD28/CTLA-4 and the pathogenesis and activity of JIA, and the results provide a basis for the development of new treatments for JIA.

The present study was limited by its relatively small sample size; clinical studies with larger sample sizes are required to further validate the results. Future studies will focus on further investigating CD28/CTLA-4 expression in different JIA subtypes and the correlation between their gene polymorphisms and JIA. 


\section{Acknowledgements}

The study was funded by the Science and Technology Fund, Qingdao China. The authors are grateful to the Qingdao Women and Children's Hospital Authority, particularly Peng Zeng, and Qingdao University Medical College. The authors thank the departmental operations managers, nurse specialists and all the registered nurses in the pediatric departments of the two hospitals who participated in and facilitated this study.

\section{References}

1. Ravelli A and Martini A: Juvenile idiopathic arthritis. Lancet 369: 767-778, 2007.

2. Thierry S, Fautrel B, Lemelle I and Guillemin F: Prevalence and incidence of juvenile idiopathic arthritis: a systematic review. Joint Bone Spine 81: 112-117, 2014.

3. Tugal-Tutkun I, Quartier P and Bodaghi B: Disease of the year: juvenile idiopathic arthritis-associated uveitis - classification and diagnostic approach. Ocul Immunol Inflamm 22: 56-63, 2014.

4. Vastert SJ, Kuis W and Grom AA: Systemic JIA: new developments in the understanding of the pathophysiology and therapy. Best Pract Res Clin Rheumatol 23: 655-664, 2009.

5. Nusman CM, van den Berg JM, Schonenberg-Meinema D, et al: Juvenile idiopathic arthritis: from biomarker to treatment. Ned Tijdschr Geneeskd 157: A6391, 2013 (In Dutch).

6. Goldzweig $\mathrm{O}$ and Hashkes PJ: Abatacept in the treatment of polyarticular JIA: development, clinical utility, and place in therapy. Drug Des Devel Ther 5: 61-70, 2011.

7. Carreno BM and Collins M: The B7 family of ligands and its receptors: new pathways for costimulation and inhibition of immune responses. Ann Rev Immunol 20: 29-53, 2002.

8. McCoy KD and Le Gros G: The role of CTLA-4 in the regulation of T cell immune responses. Immunol Cell Biol 77: 1-10, 1999.

9. Pediatric Rheumatology Collaborative Study Group in China: Diagnosis and treatment of pediatric rheumatic diseases: a consensus statement (I). Lin Chuang Er Ke Za Zhi 28: 984-991, 2010 (In Chinese).

10. He XZ: Juvenile idiopathic arthritis. Edmonton, Canada, 2001 (Draft for new classification standard for International Society of Rheumatology). Zhonghua Feng Shi Bing Xue Za Zhi 6: 62-63, 2002 (In Chinese).

11. Hu YM and Jiang ZF (eds): Zhu Futang Practical Pediatrics. 7th edition. People's Medical Publishing House, Beijing, pp667-672, 2002.

12. Grom AA and Hirsch R: T-cell and T-cell receptor abnormalities in the immunopathogenesis of juvenile rheumatoid arthritis. Curr Opin Rheumatol 12: 420-424, 2000.

13. Wang LL, Li LX, Liu Z and Feng WH: Relationship between disequilibrium of $\mathrm{T}$ lymphocyte subgroups and inflammatory adhesion molecules in patients with rheumatoid arthritis. Mian Yi Xue Za Zhi 18: 378-380, 2002 (In Chinese).
14. Li YJ and Dong WL: The last advances of study on the B7 family members. Guo Ji Mian Yi Xue Za Zhi 34: 221-226, 2011 (In Chinese).

15. Goëb V, Buch MH, Vital EM and Emery P: Costimulation blockade in rheumatic diseases: where we are? Curr Opin Rheumatol 21: 244-250, 2009.

16. Rodríguez-Palmero M, Franch A, Castell M, et al: Effective treatment of adjuvant arthritis with a stimulatory CD28-specific monoclonal antibody. J Rheumatol 33: 110-118, 2006.

17. Qi JJ, Zhang P and Xiong XH: Relationship between abnormality of costimulative molecular expression and imbalanced immune function in patients with rheumatoid arthritis. Lin Chuang Hui Cui 22: 174-176, 2007 (In Chinese).

18. Brunet JF, Denizot F, Luciani MF, et al: A new member of the immunoglobulin superfamily - CTLA-4. Nature 328: 267-270, 1987.

19. Chang TT, Kuchroo VK and Sharp AH: Role of the B7-CD28/CTLA-4 pathway in autoimmune disease. Curr Dir Autoimmun 5: 113-130, 2002.

20. Linsley PS, Greene JL, Brady W, et al: Human B7-1 (CD80) and B7-2 (CD86) bind with similar avidities but distinct kinetics to CD28 and CTLA-4 receptors. Immunity 1: 793-801, 1994.

21. Colucci F, Bergman ML, Penha-Gonçalves C, et al: Apoptosis resistance of nonobese diabetic peripheral lymphocytes linked to the Idd 5 diabetes susceptibility region. Proc Natl Acad Sci USA 94: 8670-8674, 1997.

22. Matsui T, Kurokawa M, Kobata T, et al: Autoantibodies to T cell costimulatory molecules in systemic autoimmune diseases. J Immunol 162: 4328-4335, 1999.

23. Zhang SH, Han YX and Wu JB: Expression of co-stimulatory molecules CD28/CTLA-4:B7 in peripheral blood lymphocytes of patients with ankylosing spondylitis. Zhejiang Yi Xu 28: 800-802, 2006 (In Chinese).

24. Duftner C, Dejaco C, Kullich W, et al: Preferential type 1 chemokine receptors and cytokine production of CD28- $\mathrm{T}$ cells in ankylosing spondylitis. Ann Rheum Dis 65: 647-653, 2006.

25. Zhang R, Jiang L, Li SF, et al: Expression of 4-1BB on $\mathrm{T}$ lymphocytes and relationship with $\mathrm{TH} 1 / \mathrm{TH} 2$ cytokines from patients with rheumatoid arthritis. Zhonghua Wei Sheng Wu Xue He Mian Yi Xue Za Zhi 27: 285-288, 2007 (In Chinese).

26. Vallejo AN, Nestel AR, Schirmer M, et al: Aging-related deficiency of CD28 expression in CD4+ T cells is associated with the loss of gene-specific nuclear factor binding activity. J Biol Chem 273: 8119-8129, 1998.

27. Posnett DN, Sinha R, Kabak S and Russo C: Clonal populations of $\mathrm{T}$ cells in normal elderly humans: the $\mathrm{T}$ cell equivalent to "benign monoclonal gammapathy". J Exp Med 179: 609-618, 1994.

28. Effros RB: Loss of CD28 expression on T lymphocytes: a marker of replicative senescence. Dev Comp Immunol 21: 471-478, 1997.

29. Weyand CM, Fulbright JW and Goronzy JJ: Immunosenescence, autoimmunity, and rheumatoid arthritis. Exp Gerontol 38: 833-841, 2003.

30. Vallejo AN, Weyand CM and Goronzy JJ: T-cell senescence: a culprit of immune abnormalities in chronic inflammation and persistent infection. Trends Mol Med 10: 119-124, 2004. 